\title{
Discussion on "Virtual and Real" Online Teaching Mode of Experiment Course of Color Science and Technology
}

\author{
Yanfang $\mathrm{Xu}^{*}, \mathrm{Yu}$ Liu, Yuehong Song, Xiu Li and Min Huang \\ School of Printing \& Packaging Engineering, Beijing Institute of Graphic Communication, Beijing 102600, China \\ *Corresponding author. Email: xuyanfang63@163.com
}

\begin{abstract}
Under the background of COVID-19, network experiment teaching has become a new way of experiment teaching. According to the characteristics of experiments in Color Science and Technology course, and relying on the Network Teaching Platform, the paper discusses the online experiment teaching mode of "Virtual and Real". The network experiment teaching mode includes online display of experiment related resources, pre-class preview, online virtual simulation and personal offline application after class, forming a student-based, online and offline interaction, and from operation to application of the entire experiment link. The experiment mode trains students' scientific thinking habit, self-study and self-management ability, and enhances the effectiveness of online experiment teaching.
\end{abstract}

Keywords: Network teaching, Experimental teaching mode, Virtual and Real.

\section{INTRODUCTION}

During the background of COVID-19 in the first half of 2020, universities and colleges, in response to the call for "suspended class, ongoing teaching and learning", have developed online classroom teaching activities through the Internet ${ }^{[1]}$. The courses of virtual simulation experiment on the sharing platform of National Virtual Simulation Experiment Teaching Project have been widely used [2]. Even for specialty majors like printing engineering, online teaching has become the main way [3]. But at present the network teaching mainly focuses on the theory course, the proportion of experiment and practice courses is still low.

Modern education is developing towards the direction of "Internet education", and the information technology of network teaching platform will be more abundant, online experiment teaching is bound to become an indispensable and important component of network teaching. Combing with the practice of the experiment teaching of the course "Color Science and Technology", the author discusses and practices the network experiment teaching mode.

\section{CHARACTERISTICS OF EXPERIMENTS IN "COLOR SCIENCE AND TECHNOLOGY"}

"Color Science and Technology" is the core course of printing engineering major in our university. The experiments include measurement of color light and prints, color characterization of media devices, and their applications. All of them need to be implemented with professional software and color measuring instrument, or used in professional software and control media equipment. For example, the experiment of creating color Profile of media device (a data file that records the color performance of a media device, in the firmat*.icm or *icc) needs the cooperation of the professional software, such as ilProfiler, and color measuring instrument, such as photometer. Later, the application of Profile can be practiced in profession application software such as Photoshop and Indesign to simulate or analyze the device's color performance.

Virtual simulation technology has been widely used in the experiment teaching of general courses [4], and has been used in the practice teaching of special specialty [5]. Therefore, the part of the course experiment of color measurement and Profile establishment can be done based on virtual simulation 
technology on the Internet teaching platform. In the application part, the professional application software such as Photoshop or Indesign has been widely used in the personal computer of the students of this major, and the students have the ability to work independently in an off-campus environment. These two characteristics of the course experiment are the basis of the construction of its network teaching mode.

\section{CONSTRUCTION OF NETWORK EXPERIMENT TEACHING MODE OF "VIRTUAL AND REAL"}

Whether it is a theoretical or experimental course, the first key task of network teaching is to plan and design the teaching mode. That is, according to the characteristics of the experiment and the teaching platform resources, the teaching mode can focus on teaching students how to sue the network resources to study independently and reduce the randomness of online learning [6].

In the practice of our course experiment, the teaching mode of "Virtual and Real" has been adopted in the network teaching. Here, the so-called "virtual" is that the use of virtual simulation software for the experimental process of experience and self-learning on the Internet teaching platform, and the so-called "real" is that students sue the professional software resources on personal computer to complete the analysis of the experimental results and application, and then upload the application results or experimental reports to the teaching platform.

With the help of the Internet teaching platform, this process of "combination of virtual and real" form a complete experimental chain, including the experimental content preview, experimental experience and applications based on the personal online and offline interaction. It involves the following three processes.

\subsection{Construction of Experimental Teaching Resources}

The construction of teaching resources suitable for the study on Internet teaching platform is the primary work for the quality assurance of network teaching.

During the COVID-19, the university has launched the "learning through" Internet teaching platform. In addition to the common teaching courseware resources of General Education, the platform can also upload the format files such as PPT courseware, Word document and video developed by teachers themselves, for students to learn online. Also, the platform has the functions Teaching Publishing Homework (and giving answers at the same time), student submitting homework, online examination, examination questions and result analysis, and student management. Based on this, the experimental teaching material resources suitable for this teaching platform are specially designed and established, including materials for preview, experimental demonstration videos, virtual simulation experimental tools and results analysis, report writing reference materials. These experimental materials display the basic knowledge and implementation technology of experiment in all aspects, and provide effective resources for students' autonomous learning.

\subsection{Previewing the Experiment}

Before the experiment, arrange the content and requirements of the experiment in the way of screen sharing in the online class, and load the experimental materials and some questions to the teaching platform, so as to guide the students to carry out independent and exploratory learning. For example, before the experiment of "The establishment and analysis of display Profile", the following questions were posed: How the colors of a display screen come into being? How do I control the display screen to display the desired color? And so on. The problems are related to the purpose and significance of the experiment.

Combining with the experiment principle and process, the questions "how to form the white-field color of the display screen?", and "how to change the luminous intensity of the single channel of the display?". These problems are related to the selection of parameters for building the display Profile, not only decide the performance of the Profile, but also directly determine the color and tonal character of the image displayed on the screen. So, these questions encourage students to learn, think, and form an understanding of practical techniques, not only consolidated the basic knowledge, understood the experimental principle, clarified the experimental step and significance, but also stimulated the enthusiasm of explore the scientific issues. At the same time, it also plays the role of enlightening students' scientific thinking and cultivating their ability of analyzing and solving scientific problems.

\subsection{Online Virtual Simulating the Experiment}

During the week of the experiment, the PPT file of the virtual simulation experiment tool is uploaded to the learning platform, and the students can finish the experiment online, and finish the application and analysis of experiment results off line, and submit it to the learning platform.

Copy the screenshot of each step of creating a device's Profile in professional software to the PPT document page, and make full use of the various functional tools available on PPT pages included 
controlling the jump and return of the page, to simulate the actually process of creating a Profile in professional software, forming a virtual simulation experiment tool. In that, a database of Profile files corresponding to different device parameters was created in advance, and corresponding to the parameters in the PPT page with different playing order, so as to simulate different experiment results. For example, in the case of creating a CMYK output device Profile, the database contains a number of Profile files corresponding to different total ink parameters, and named for different files, at the end of the experiment process, students can find the result of the personalized Profile (equivalent to their own unique output device) according to the parameters they choose. In addition, each experiment step is equipped with the corresponding knowledge points and matters needing attention, so as to guide the students to pay attention to and analyze the technique details of the experiment process, and to cultivate the students' meticulous and careful scientific thinking habits.

This virtual simulation process not only enables students to simulate the process of creating device Profile with professional software, but also forms personalized experimental results.

\subsection{Analysis and Application of Experimental Results}

At the end of the virtual simulation experiment, the analysis of experimental results and the extra-curricular application are required.

Students select their own experimental results from the results database of the learning platform, and analyze and apply the results using professional software such as Photoshop or Indesign on their personal computers, and answer questions. Furthermore, write an experiment report and submit it to the learning platform. For example, for the Profile under the condition of different total ink limit, the application in Photoshop can form different output minimum brightness data, which is the personalized result, and analyze and answer questions accordingly. The analysis of individual experiment results and the answer of thinking questions can avoid the phenomenon of plagiarism to a certain extent.

Based on this, an experimental teaching chain suitable for the combination of virtual and real experiments has been formed by means of network information, which not only ensures the teaching quality of network experiment teaching, but also play a role in stimulating students' learning enthusiasm and cultivating students' autonomous learning ability.

\section{EXPERIENCE AND THINKING}

According to the experience of the network teaching, the students can learn the operation method, basic knowledge and application technology, and agree with the network teaching process. However, online simulation-based experimental teaching is not a real process after all, has advantages, but also needs to be improved.

\subsection{Advantages of Network Experiment Teaching}

The network teaching may enable students to study the related knowledge of experiment, watch the experiment video, operate and practice the experiment process in a virtual way, not bounded by time and space.

In addition, it is realized that the experimental teaching of Color Science and Technology using virtual simulation technology can solve the problems of high cost and high consumption in creating Profile of a real printing press. The online virtual simulation is convenient and efficient, which improves the efficiency of experiment teaching. This is also recognized in the online experimental teaching of other subjects [2].

Thirdly, network teaching can rely on the teaching platform, rich and concentrated learning resources, easy for students to learn. Homework management and student tracking management system, easy for teachers to use information to grasp the situation of the students, improve the teaching level.

\subsection{Problems of Network Experiment Teaching}

First of all, the function of teaching platform is not perfect. It shows that the operation is not stable enough, and there are few kinds of documents, mainly word document, PPT courseware and video, and the support of experiment teaching with professional characteristics is not enough.

Secondly, the network experiment teaching resource is not enough. The experimental teaching resources of specialized courses are mainly constructed by teachers themselves, which cannot meet the requirement of improving teaching quality. There is an urgent need for the professional development team and teachers to work together to develop teaching design and information construction, so as to achieve the professionalization of teaching content and interaction dynamic process.

Thirdly, teachers' information literacy needs to be improved. The effective implementation of network teaching depends on the information-based conditions and teachers' information-based literacy, among which teachers' factors play a leading role [7]. To ensure the quality of network teaching, especially the quality of 
network teaching of experimental courses, teachers should have the awareness, ability and technique of information-based teaching.

\section{CONCLUSIONS}

With the help of network teaching platform, the method of "Virtual and Real" can be carried out in the experiment teaching under the background of COVID19 prevention and control normalization. In this method, the online virtual simulation and the students' independent offline practice are taken as the two cores, and the network resources and learning management function are combined to form a complete teaching and learning process of experimental teaching.

In addition, this method is helpful for students to master practical knowledge, stimulate their study enthusiasm, cultivate their ability of self-study and selfmanagement, and ensure the quality of experiment teaching to a certain extent. It is a beneficial choice of network experiment teaching under the background of COVID-19 prevention and control normalization.

\section{ACKNOWLEDGMENTS}

This study is funded by General Key Teaching Reform Project of Beijing Institute of Graphic Communication (No. 22150120028/009).

\section{REFERENCES}

[1] H.F. Jiang, Y.p. Liu, B. Zhang, Research on behavior choice, motivation and countermeasures of teaching reform in colleges and universities under online education mode, in: Heilongjiang Researches on Higher Education, No.1, 2021, pp.150-155. DOI: 10.19903/j.cnki.cn23-1074/g. 2021.01.026
[2] Working Groupon Experiment Space Operation of Higher Education Press, Application and analysis of virtual simulation experiment teaching project on spring semester of 2020, in: Teaching in Chinese universities, No.11, 2020, pp.81-84.

[3] J. Geng, C.G. Cao, Exploration and Practice of the Network Teaching Method of Color Management Principles and Technologies, in: DIGITAL PRINTING, No.3, 2020, pp.41-44. DIO 10.19370/j.cnki.cn10-1304/ts.2020.03.007

[4] H. An, X.Y. Mu, O. Tao, X.Y. Zhan, X.G. Gao. Innovative Practice of Physics Experiment Teaching Mode Based on Virtual Simulation Technology, in: CHINESE MEDICINE MODERN DISTANCE EDUCATION OF CHINA, Vol.18, No.23, 2020, pp.6-8. DOI:10.3969/j.issn.16722779.2020.23.003

[5] G.D. Liu, L.H. Guo, Z.A. Liu, Z.J. Li, Construction and Application of Practice Online Course Majoring in Printing Engineering Based on Network Teaching Platform, in: DIGITAL PRINTING, No.3, 2020, pp.133-138. DOI 10.19370/j.cnki.cn10-1304/ts.2020.03.023

[6] W.Y. Chen, H.L. Cao, Current situation and thinking of online teaching on "double-first-class" universities, in: Educational Science, Vol.36, No.2, 2020, pp. 24-30.

[7] D.D. Zhao, Y.M. Zhu,Teaching reform guided by information technology and its discrimination-A concurrent discussion on "screen changes destiny", in: Audio-visual education in China. No.11, 2019, pp.41-48. 